Rev. Bras. Saúde Prod. Anim., Salvador, v.17, n.4, p.719-728 out./dez., 2016 http://www.rbspa.ufba.br

\title{
Prebiótico e antibiótico como aditivos nas rações pré e pós-alojamento para frangos de corte
}

\author{
Prebiotic and antibiotics as additives in the pre-and post-placement broilers
}

\author{
REIS, Túlio Leite ${ }^{1 *}$; CALIXTO, Lígia Fátima Lima ${ }^{1}$, LIMA, Marcos Fabio de ${ }^{1}$; \\ LEMOS, Marina Jorge de ${ }^{1}$; ALVES, Osvanira dos Santos ${ }^{1}$; CORDIDO, Karoll Andrea \\ Alfonso Torres ${ }^{2}$; CURVELLO, Fernando Augusto ${ }^{1}$; SOUSA, Felipe Dilelis de Resende ${ }^{1}$
}

\footnotetext{
${ }^{1}$ Universidade Federal Rural do Rio de Janeiro, Departamento de Produção Animal, Programa de PósGraduação em Zootecnia, Seropédica, Rio de Janeiro, Brasil.

${ }^{2}$ Universidade Estadual do Norte Fluminense Darcy Ribeiro, Centro de Ciências e Tecnologias Agropecuárias, Laboratório de Zootecnia, Campos dos Goytacazes, Rio de Janeiro, Brasil.

*Endereço para correspondência: tulioreis@hotmail.com
}

\section{RESUMO}

Objetivou-se avaliar o uso de rações, contendo prebiótico ou antibiótico, nas fases pré e pósalojamento sobre o desempenho de frangos de corte. Foram utilizados 720 pintos de um dia, machos, da linhagem Cobb-500, distribuídos em blocos casualizados com quatro tratamentos, com seis repetições de 30 aves cada. Os tratamentos consistiram em: Antibiótico - aves que consumiram ração com adição de antibiótico nas fases pré e pós-alojamento; Prebiótico - aves que consumiram ração com adição de prebiótico nas fases pré e pósalojamento; Sem aditivo- aves que consumiram ração sem aditivo nas fases pré e pósalojamento; Jejum - aves que permaneceram em jejum na fase pré-alojamento e consumo de ração com antibiótico nas fases pós-alojamento. O fornecimento de ração pré-alojamento, dentro das caixas de transporte se iniciou no incubatório, sendo o tempo pré-alojamento de 24 horas. Para avalição do desempenho produtivo das aves, aferiram-se as variáveis de: peso médio, consumo de ração, ganho de peso, conversão alimentar, fator de produção e viabilidade criatória. A utilização de ração préalojamento com prebiótico ou antibiótico promoveu melhorias significativas $(\mathrm{P}<0,05)$ no peso vivo e no ganho de peso dos pintos na fase de 1 a 7 dias. Tal fato ocorreu, independente do uso de aditivos nas rações fornecidas no préalojamento e na fase pré-inicial. O desempenho final dos frangos de corte não foi influenciado $(\mathrm{P}>0,05)$ pela utilização de aditivo nas fases de pré e pós-alojamento. Assim, conclui-se que o fornecimento de ração pré-alojamento não é necessária para frangos de corte, no período de jejum testado.

Palavras-chave: mananoligossacarídeo, desempenho, nutrição neonatal, parede celular

\section{SUMMARY}

This study aimed to evaluate the use of feed containing prebiotic or antibiotic, in the pre and post accommodation on the performance of broilers. We used 720 day-old chicks, males, Cobb-500 strain, distributed in randomized blocks with four treatments with six replicates of 30 birds each. The treatments consisted of: Antibiotic - birds fed diet with added antibiotics in pre- and post-housing; Prebiotic - birds fed feed with added prebiotic in pre and post accommodation; No aditivo- birds fed without feed additive in pre- and post-housing; Fasting birds fasted in the pre-stage housing and feed intake with antibiotics in the post-stage housing. The provision of pre-feed accommodation within the transport boxes started in the incubator, and the pre-accommodation time of 24 hours. For productive performance analysis of bird, have assessed the variables of: average weight, feed intake, weight gain, feed conversion, production factor and production viability. The use of pre-accommodation prebiotic or antibiotic property diet resulted in 
significant improvements $(\mathrm{p}<0.05)$ in body weight and weight gain of chicks in step 1 to 7 days. This happened regardless of the use of additives in feed provided the pre-housing and pre-initial phase. The final performance of broilers was not affected $(\mathrm{P}>0.05)$ for the use of additives in the pre and post accommodation. Thus, it is concluded that the supply of prehousing portion is not required for broilers tested in fasting period.

Keywords: mannanoligosaccharides, performance, neonatal nutrition, cell wall

\section{INTRODUÇÃO}

O rendimento da incubação artificial bem como à qualidade do pintinho são aspectos que podem afetar o peso final do frango. Neste sentido, algumas estratégias podem ser utilizadas para melhorar o peso inicial desse pintinho ao alojamento. Tem sido reportado que $o$ fornecimento imediato de ração (durante o transporte entre $\mathrm{o}$ incubatório e o galpão onde ocorrerá o alojamento), aliado à uma adequada saúde intestinal podem sanar esse problema. A ocorrência de nascimentos desuniformes (que podem propiciar uma janela de nascimento de 36 horas desde os primeiros ovos eclodidos, até a retirada de todos os pintinhos), somado ao tempo gasto nos processos de sexagem e vacinação, ocorridos no incubatório, e transporte até a granja, onde os pintos de corte podem chegar com mais de 48 horas após o nascimento, quando só então terão acesso ao alimento (DALMAGRO, 2012). Estudos tem evidenciado que entre outras vantagens, essa alimentação fornecida imediatamente após a eclosão acelera o desenvolvimento morfológico do intestino delgado (NOY \& SKLAN, 1998) enquanto que a demora no acesso à ração atrasa o desenvolvimento da mucosa intestinal (UNI et al., 1998; GEYRA et al., 2001).
Logo após a eclosão ocorre a colonização do trato gastrointestinal por microorganismos (fungos, bactérias e protozoários), que em condições normais vivem em equilíbrio. Contudo, devido às condições de estresse neste período, pode ocorrer prejuízo na flora intestinal. Com o intuito de reduzir este efeito, o fornecimento de aditivos melhoradores de desempenho e equilibradores da microflora (antibióticos e prebióticos, respectivamente) na dieta de frangos de corte podem aumentar essa população benéfica de microorganismos, criando um ambiente favorável à sua colonização e proliferação. Devido a proibição do uso de antibióticos como aditivos pela União Europeia, vem surgindo um grande interesse no desenvolvimento de pesquisas com a utilização de substâncias que possam substituí-los. Os prebióticos tem se destacado pela sua capacidade de manutenção do equilíbrio benéfico da microbiota intestinal, melhoria da integridade do epitélio intestinal e consequentemente maior absorção de nutrientes, principalmente nos primeiros dias de vida das aves (IJI et al., 2001).

Diante do exposto, o objetivo foi avaliar o uso de rações contendo prebiótico e/ou antibiótico nos períodos pré e pósalojamento sobre o desempenho produtivo de frangos de corte.

\section{MATERIAL E MÉTODOS}

O estudo teve início no incubatório Rio Minas da empresa Reginaves Indústria e Comércio de Aves Ltda, localizado na cidade de São José da Lapa no estado de Minas Gerais. Os pintos foram alojados para avaliação de desempenho no Cento de Pesquisas Avícolas (CPA) do Instituto Federal do Rio de Janeiro (IFRJ), localizado no município de Pinheiral, estado do Rio de Janeiro, 
durante no período de 9 de novembro à 21 de dezembro de 2012.

Foram utilizados 720 pintos recémeclodidos, machos, da linhagem Cobb, distribuídos em blocos ao acaso, com quatro tratamentos, cada um tendo 6 repetições de 30 aves cada. Dois blocos representaram o peso médio dos pintos ao nascimento $(39,77 \mathrm{~g} \pm 1,8 \%$ e $40,66 \mathrm{~g} \pm$ $0,89 \%$ ). Os tratamentos consistiram em: Antibiótico - aves que consumiram ração com adição de antibiótico (Avilamicina, 55ppm de Surmax 200) nas fases pré e pós-alojamento; Prebiótico - aves que consumiram ração com adição de prebiótico (MOS, 1000ppm de ImmunoWall) nas fases pré e pósalojamento; Sem aditivo - aves que consumiram ração sem aditivo nas fases pré e pós-alojamento; Jejum - aves que permaneceram em jejum na fase préalojamento e consumo de ração com antibiótico nas fases pós-alojamento. A fase pré-alojamento, incluiu o período em que no incubatório os pintos foram condicionados em caixas de transporte forradas com papel corrugado e marcadas de acordo com o tratamento, e foi fornecida ração formulada para a fase préinicial (Tabela 1) dentro da caixa, na quantidade de $2 \mathrm{~g}$ por ave, conforme as recomendações de Agostinho et al. (2012) e de acordo com o tratamento correspondente (Antibiótico, Prebiótico e Sem aditivo). O período pré-alojamento (trajeto incubatório - granja) foi de 24 horas. No galpão experimental (fase pósalojamento, a partir do alojamento até a retirada para o abate ), os pintos foram pesados individualmente, para obter o peso após o pré-alojamento. Posteriormente foram alojados nos boxes formando seis unidades experimentais de 30 aves (10aves $/ \mathrm{m}^{2}$ ), por cada tratamento, iniciando-se o período experimental pósalojamento. Cada box de $3 \mathrm{~m}^{2}$ foi equipado com comedouro tubular, Tabela 1. Composição das rações experimentais bebedouros tipo nipple e cama nova, composta de maravalha. O programa de iluminação utilizado foi de 24 horas de luz durante todo o período experimental. $\mathrm{O}$ fornecimento de ração e de água foi $\mathrm{ad}$ libitum. As dietas experimentais foram isonutritivas e isocalóricas, formuladas a base de milho e de farelo de soja, atendendo os níveis de necessidades nutricionais estabelecidos por Rostagno et al. (2011). As rações foram formuladas para as fases de criação pré-inicial de $1 \mathrm{a}$ 7 dias, inicial de 8 a 21 dias, crescimento de 22 a 35 dias e final de 36 a 40 dias, conforme apresentado na Tabela 1.

Um material inerte (caulim) foi utilizado permitindo a manutenção dos mesmos níveis nutricionais em todas as rações. Os tratamentos que não receberam aditivos prebióticos e antibióticos foi adicionado $1500 \mathrm{ppm}$ de caulim. Para os tratamentos que houve inclusão de prebiótico foi utilizado 1000ppm de ImmunoWall (MOS) +500 ppm de caulim, os com tratamentos com inclusão de antibiótico, foi adicionado 55ppm de Surmax $200+$ $1445 \mathrm{ppm}$ de caulim. A quantidade do prebiótico e do antibiótico utilizada foi a mesma recomendada pelo fabricante conforme rótulo do produto.

Foram analisadas semanalmente as variáveis de desempenho: peso médio (g), ganho de peso médio $(\mathrm{g})$ consumo médio de ração (g) e conversão alimentar para os períodos acumulados de 1 a 7,1 a 14,1 a 21,1 a 28,1 a 35 e 1 a 40 dias. Foi calculado também o ganho de peso $(\mathrm{g})$ e a conversão alimentar acumuladas. Aos 40 dias foram analisadas as variáveis: viabilidade e fator de produção $[(\mathrm{FP}=$ ganho de peso diário $(\mathrm{Kg}) \mathrm{x}$ Viabilidade $\mathrm{x}$ 100)/ conversão alimentar)] de acordo com Agostinho et al. (2012).

Esse trabalho foi submetido e aprovado pela Comissão de Ética no Uso de Animais da UFRRJ, Protocolo $\mathrm{N}^{\mathrm{o}}$ 192/2012. 
Rev. Bras. Saúde Prod. Anim., Salvador, v.17, n.4, p.719-728 out./dez., 2016 http://www.rbspa.ufba.br ISSN 15199940

\begin{tabular}{|c|c|c|c|c|}
\hline Ingredientes $(\%)$ & $\begin{array}{c}\text { Ração } \\
\text { Pré-inicial } \\
\text { (1-7 dias) }\end{array}$ & $\begin{array}{c}\text { Ração } \\
\text { Inicial } \\
\text { (8-21 dias) } \\
\end{array}$ & $\begin{array}{c}\text { Ração } \\
\text { Crescimento } \\
\text { (22-35 dias) }\end{array}$ & $\begin{array}{c}\text { Ração } \\
\text { Final } \\
\text { (36-40 dias) }\end{array}$ \\
\hline Milho $(8.55 \%$ PB $)$ & 58,2909 & 62,0290 & 64,000 & 67,5187 \\
\hline Farelo de Soja (45.96\% PB) & 32,2372 & 28,5065 & 27,2430 & 24,0000 \\
\hline Farinha de Carne e ossos $(44.10 \%$ PB $)$ & 7,3649 & 6,6781 & 5,0000 & 4,5000 \\
\hline Óleo de soja & 0,5102 & 1,3740 & 2,2651 & 2,4482 \\
\hline Sal & 0,3787 & 0,3515 & 0,3684 & 0,3645 \\
\hline Cloreto de colina & 0,0500 & 0,0500 & 0,0500 & 0,0500 \\
\hline Suplemento mineral ${ }^{1}$ & 0,0500 & 0,0500 & 0,0500 & \multirow{2}{*}{$0,2000^{3}$} \\
\hline Suplemento vitamínico ${ }^{2}$ & 0,0500 & 0,0500 & 0,0500 & \\
\hline DL-Metionina & 0,3586 & 0,2953 & 0,2945 & 0,2736 \\
\hline L-Lisina HCL & 0,3454 & 0,3014 & 0,3289 & 0,3483 \\
\hline L-Treonina & 0,1641 & 0,1017 & 0,1452 & 0,1467 \\
\hline Coccidiostático & $0,0500^{4}$ & $0,0625^{5}$ & $0,0550^{6}$ & - \\
\hline Aditivo $^{7}$ & 0,150 & 0,150 & 0,150 & 0,150 \\
\hline Total & 100 & 100 & 100 & 100 \\
\hline \multicolumn{5}{|l|}{ Composição nutricional calculada } \\
\hline Energia metabolizável (Mcal/Kg) & 2,960 & 3,050 & 3,150 & 3,200 \\
\hline Proteína Bruta $(\mathrm{PB} \%)$ & 22,4 & 21,2 & 19,8 & 18,4 \\
\hline Cálcio $(\mathrm{Ca} \%)$ & 0,920 & 0,841 & 0,758 & 0,663 \\
\hline Fósforo disponível (P\%) & 0,470 & 0,401 & 0,354 & 0,309 \\
\hline Cloro $(\%)$ & 0,2 & 0,19 & 0,18 & 0,17 \\
\hline Sódio (\%) & 0,22 & 0,21 & 0,20 & 0,195 \\
\hline Potássio (\%) & 0,59 & 0,585 & 0,58 & 0,58 \\
\hline Lisina Digestível (\%) & 1,324 & 1,217 & 1,131 & 1,060 \\
\hline
\end{tabular}

Composição/ kg de produto: ${ }^{\mathrm{I}} \mathrm{Mn}$ 150.000,000 ppm; Zn 140.000,000 ppm; Fe 90.000,000 ppm; Cu $16.000,000 \mathrm{ppm}$; I 1.500,000 ppm; Se 87,500 ppm. ${ }^{2}$ Vit A 16.000,000; Vit D3 4.000,000 KUI/Kg; Vit E 30.000,000 UI/Kg; Vit K3 3.600,000 Mg/Kg; Vit B1 3.600,000 Mg/Kg; Vit B2 $12.000,000 \mathrm{Mg} / \mathrm{Kg}$;

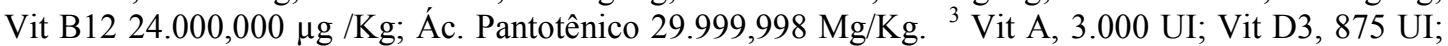
Vit E, 10.000 UI; Vit K3, $1.000 \mathrm{mg}$; Vit B1, $1.000 \mathrm{mg}$; VitB2, $2.500 \mathrm{mg}$; Vit B6, $1.625 \mathrm{mg}$; VitB12, $5.000 \mathrm{mg}$; Ac. Pantotênico,5.000 mg; Niacina, $12.500 \mathrm{mg}$; Ac Fólico, 625mg; Biotina, $55 \mathrm{mg}$; Manganês, 30.000 ppm; Zinco, 25.000 ppm; Ferro, 16.250 ppm; Cobre, 2.500 ppm; Iodo; 375 ppm; Selênio, 87,500 ppm; Antioxidante, 166,5 mg. ${ }^{4}$ Nicarbazina $110 \mathrm{ppm} . \quad{ }^{5}$ Narasina $80 \mathrm{~g} / \mathrm{kg}+$ Nicarbazina $80 \mathrm{~g} / \mathrm{kg} .{ }^{6}$ Salinomicina $120 \mathrm{~g} / \mathrm{kg}$.

${ }^{7}$ Tratamentos com inclusão de prebiótico : 1000 ppm de ImmunoWall (MOS) + 500 ppm de caulim; Tratamentos com inclusão de antibiótico: Surmax 200 (Avilamicina) $55 \mathrm{ppm}+1445 \mathrm{ppm}$ de caulim e Tratamentos sem aditivo: $1500 \mathrm{ppm}$ de caulim.

Os dados foram analisados em delineamento em blocos ao acaso com repetição dentro do bloco utilizando modelos mistos, sendo o tratamento (3 graus de liberdade, GL) e o bloco (1 GL) considerados como efeitos fixos e a interação entre tratamento e bloco aninhado dentro da repetição e o resíduo foram considerados como efeitos aleatórios. Foi utilizado o procedimento MIXED do SAS (versão
9.0). Quando significativa, as médias entre tratamentos foram comparadas usando a diferença mínima significativa de Fisher (i.e. a opção DIFF do comando LSMEANS). A significância foi declarada a $P \leq 0,05$. 
Rev. Bras. Saúde Prod. Anim., Salvador, v.17, n.4, p.719-728 out./dez., 2016 http://www.rbspa.ufba.br

\section{RESULTADOS E DISCUSSÃO}

O fornecimento de ração na fase préalojamento influenciou positivamente $o$ peso médio e o ganho de peso dos pintos de corte de 0 a 7 dias $(\mathrm{P}<0,05)$ independente da inclusão e do tipo de aditivo usado na formulação da ração consumida na fase pré-inicial (Tabela 2). No entanto, não houve efeito no consumo de ração e na conversão alimentar, no mesmo período $(\mathrm{P}>0,05)$.

Tabela 2. Desempenho produtivo de frangos de corte alimentados com ração pré e pósalojamento nas fases de 1 a 7,1 a14 e 1 a 21 dias de idade

\begin{tabular}{|c|c|c|c|c|}
\hline Tratamentos & Peso (g) & $\begin{array}{c}\text { Ganho } \\
\text { de peso }(\mathrm{g})\end{array}$ & $\begin{array}{c}\text { Consumo } \\
\text { de ração (g) }\end{array}$ & $\begin{array}{c}\text { Conversão } \\
\text { alimentar }(\mathrm{g} / \mathrm{g})\end{array}$ \\
\hline \multicolumn{5}{|l|}{1 a 7 dias } \\
\hline Sem aditivo & $174 \mathrm{a}$ & $137 \mathrm{a}$ & 156 & 1,14 \\
\hline Antibiótico & $176 \mathrm{a}$ & $137 \mathrm{a}$ & 157 & 1,14 \\
\hline Prebiótico & $176 \mathrm{a}$ & $138 \mathrm{a}$ & 156 & 1,15 \\
\hline Jejum & $169 \mathrm{~b}$ & $131 \mathrm{~b}$ & 153 & 1,15 \\
\hline SEM & 1,23 & 1,27 & 2,95 & 0,09 \\
\hline \multicolumn{5}{|l|}{$\mathrm{P}-$ valor } \\
\hline Tratamento (T) & 0,003 & 0,007 & 0,726 & 0,999 \\
\hline Bloco $(B)^{1}$ & 0,550 & 0,946 & 0,427 & 0,961 \\
\hline $\mathrm{T}^{*} \mathrm{~B}$ & $0,033^{2}$ & 0,063 & 0,115 & 0,973 \\
\hline \multicolumn{5}{|l|}{1 a 14 dias } \\
\hline Sem aditivo & 501 & 463 & 429 & 0,94 \\
\hline Antibiótico & 510 & 471 & 443 & 0,95 \\
\hline Prebiótico & 494 & 456 & 436 & 0,95 \\
\hline Jejum & 488 & 451 & 429 & 0,91 \\
\hline SEM & 5,13 & 5,18 & 9,09 & 0,07 \\
\hline \multicolumn{5}{|l|}{$\mathrm{P}$ - valor } \\
\hline Tratamento $(\mathrm{T})$ & 0,057 & 0,069 & 0,635 & 0,977 \\
\hline Bloco $(B)^{1}$ & 0,163 & 0,218 & 0,840 & 0,992 \\
\hline $\mathrm{T} * \mathrm{~B}$ & 0,384 & 0,418 & 0,263 & 0,868 \\
\hline \multicolumn{5}{|l|}{1 a 21 dias } \\
\hline Sem aditivo & 1000 & 962 & 1114 & 1,16 \\
\hline Antibiótico & 972 & 934 & 1101 & 1,18 \\
\hline Prebiótico & 950 & 911 & 1086 & 1,19 \\
\hline Jejum & 975 & 937 & 1100 & 1,17 \\
\hline SEM & 12,1 & 12,1 & 14,5 & 0,01 \\
\hline \multicolumn{5}{|l|}{$\mathrm{P}-$ valor } \\
\hline Tratamento (T) & 0,070 & 0,065 & 0,613 & 0,294 \\
\hline Bloco $(B)^{1}$ & 0,007 & 0,008 & 0,057 & 0,228 \\
\hline $\mathrm{T} * \mathrm{~B}$ & 0,875 & 0,890 & 0,596 & 0,865 \\
\hline
\end{tabular}

Tratamentos: Sem aditivo - Ração sem aditivo nas fases pré e pós-alojamento; Antibiótico - Ração com antibiótico nas fases pré e pós-alojamento; Prebiótico - Ração com prebiótico nas fases pré e pósalojamento; Jejum - Jejum na fase pré-alojamento e ração sem aditivo na fase pós-alojamento.

Médias com letras iguais na coluna não diferem entre si (comparação usando a diferença mínima significativa de Fischer 5\%).

${ }^{1}$ Blocos: peso médio dos pintinhos no incubatório de 39,77 g (bloco 1) ou de 40,66 g (bloco 2); ${ }^{2} \mathrm{~A}$ interação do tratamento pelo bloco foi dada porque para o tratamento 1 teve diferença no peso aos 7 dias entre os blocos $1(173,45 \mathrm{~g})$ e $2(175,19 \mathrm{~g})$, mas para os outros tratamentos não houve diferenças entre os blocos. 
Dalmagro (2012) descreve que o acesso precoce à alimentação promove utilização imediata da gema residual, assim como o desenvolvimento do sistema digestório cujo maior crescimento alométrico ocorre após a eclosão quando a ave passa a consumir alimento. Outro fator influenciado pela nutrição precoce é o estabelecimento da microbiota intestinal, que está atrelada à manutenção da integridade do intestino promovendo melhor absorção dos nutrientes. Agostinho et al. (2012), também utilizando 24 horas de jejum, verificaram que aves que consumiram ração no período de pré-alojamento obtiveram melhor desempenho aos 7 dias, em comparação com aves que ficaram em jejum. No entanto, Saki (2005) não encontrou diferença significativa para consumo de ração e conversão alimentar entre aves que consumiram ração logo após a eclosão, aves que consumiram somente fubá de milho e aves em jejum de 12 horas e de 24 horas. Contudo às aves alimentadas com ração no período pré-alojamento obtiveram peso significativamente maior aos 7 dias.

A utilização de aditivos na ração na fase pré-alojamento não influenciou $(\mathrm{P}<0,05)$ o desempenho apresentado de 0 a 7 dias. Sendo que o melhor desempenho apresentado pelas aves que receberam a ração pré-alojamento, se deve ao fornecimento da própria ração e os nutrientes contidos nela e não da inclusão de prebiótico ou de antibiótico. Os prebióticos são aditivos adicionados na ração com o objetivo principal de modular a flora microbiana. No entanto, durante a fase pré-inicial ( 0 a 7 dias) não ocorre ainda à estabilidade da microbiotra intestinal, que irá acontecer por volta dos 14 dias de idade. Ainda, dependendo dos desafios do ambiente essa instabilidade pode durar até a $5^{\text {a }}$ semana de vida da ave (CANALLI et al., 1996).
O fornecimento de ração pré-alojamento, assim como a utilização de aditivos, independente do tipo (antibiótico ou prebiótico) não influenciou $(\mathrm{P}<0,05)$ as variáveis de desempenho a partir de 14 dias de idade dos frangos (períodos de 14 a 40 dias idade dos frangos) (Tabelas $2 \mathrm{e}$ 3 ). Corroborando com este experimento Agostinho et al. (2012) encontraram maior peso médio aos 14 dias para aves que consumiram ração no perído de préalojamento em comparação com aves que ficaram em jejum de 24 horas, com ausência de efeito a partir da segunda semana. No entanto, Noy \& Sklan (2000) ao fornecerem ração logo após a eclosão de pintos de corte, obtiveram frangos de 100 a $200 \mathrm{~g}$ mais pesados aos 40 dias, comparados aos pintos em jejum de 36 horas.

Pedroso et al. (2006) compararam pintos que permaneceram em jejum, com pintos alimentados logo após o nascimento. A partir de então, observaram que o jejum pós-eclosão de 24 horas não altera o peso médio, a conversão alimentar e o consumo de ração aos 21 dias de vida dos frangos. No entanto, quando o tempo de jejum aumenta para 48 horas há menor consumo e ganho de peso dos frangos. Logo, foi possível concluir que quanto maior o tempo de jejum, maior é a perda de qualidade do pintinho. Corless \& Sell (1999), em estudos com perus, encontraram diferença significativa $(\mathrm{P}<0,01)$ para peso corpóreo das aves com 7, 14, 21 dias de idade, quando deixadas em jejum pré-alojamento por 6 horas, 30 horas e 54 horas, permitindo aos autores concluir que quanto maior $\mathrm{o}$ tempo entre o nascimento e o alojamento, menor é o peso das aves nessas idades.

Neste sentido, a partir do presente experimento constata-se que os ganhos em desempenho obtidos nos frangos, com o uso da ração pré-alojamento tende a se restringir às primeiras semanas de vida do lote e tem relação direta com o tempo de 
Rev. Bras. Saúde Prod. Anim., Salvador, v.17, n.4, p.719-728 out./dez., 2016 http://www.rbspa.ufba.br

jejum que as aves sofrem. Portanto, o tempo de jejum aplicado no presente estudo (cerca de 24 horas) pode não ter sido suficiente para promover uma perda de desempenho inicial que não possa ser reparada nas fases subsequentes de desenvolvimento do frango. A restrição da ingestão de alimentos provocada pelo jejum que é submetido às aves durante $o$ período pré-alojamento, diminui $\mathrm{o}$ crescimento dos frangos, porém, essa redução no ganho de peso pode ser compensada após um período de realimentação (FONTANA et al., 1992). $\mathrm{O}$ fenômeno do ganho compensatório, provêm da redução das exigências de mantença durante $\mathrm{o}$ período de realimentação, e quanto maior a severidade da restrição do alimento, maior o período de recuperação exigido. (MAZZUCO et al., 2000).

Tabela 3. Efeito do uso de aditivos antibiótico ou prebiótico na ração pré- alojamento (trajeto incubatório-granja) e pós-alojamento sobre o desempenho de frangos de corte nas fases de crescimento e final

\begin{tabular}{|c|c|c|c|c|}
\hline Tratamentos & Peso (g) & $\begin{array}{l}\text { Ganho de } \\
\text { peso }(\mathrm{g})\end{array}$ & $\begin{array}{c}\text { Consumo } \\
\text { de ração (g) }\end{array}$ & $\begin{array}{c}\text { Conversão } \\
\text { alimentar }(\mathrm{g} / \mathrm{g})\end{array}$ \\
\hline \multicolumn{5}{|c|}{ Período de 1 a 28 dias } \\
\hline Sem aditivo & 1466 & 1429 & 1939 & 1,34 \\
\hline Antibiótico & 1517 & 1478 & 1950 & 1,33 \\
\hline Prebiótico & 1496 & 1458 & 1949 & 1,33 \\
\hline Jejum & 1470 & 1432 & 1928 & 1,35 \\
\hline SEM & 76,46 & 76,66 & 75,01 & 0,05 \\
\hline \multicolumn{5}{|l|}{$\mathrm{P}$ - valor } \\
\hline Tratamento $(\mathrm{T})$ & 0,950 & 0,953 & 0,330 & 0,990 \\
\hline Bloco (B) ${ }^{1}$ & 0,637 & 0,642 & 0,681 & 0,424 \\
\hline Interação $\mathrm{T} * \mathrm{~B}$ & 0,976 & 0,977 & 0,211 & 0,757 \\
\hline \multicolumn{5}{|c|}{ Período de 1 a 35 dias } \\
\hline Sem aditivo & 2093 & 2056 & 2929 & 1,42 \\
\hline Antibiótico & 2147 & 2108 & 2936 & 1,39 \\
\hline Prebiótico & 2141 & 2103 & 2938 & 1,41 \\
\hline Jejum & 2079 & 2041 & 2903 & 1,42 \\
\hline SEM & 148 & 148 & 173 & 0,02 \\
\hline \multicolumn{5}{|l|}{$P$ - valor } \\
\hline Tratamento $(\mathrm{T})$ & 0,963 & 0,962 & 0,469 & 0,534 \\
\hline Bloco $(\mathrm{B})^{1}$ & 0,802 & 0,803 & 0,283 & 0,029 \\
\hline Interação $\mathrm{T} * \mathrm{~B}$ & 0,997 & 0,996 & 0,519 & 0,935 \\
\hline \multicolumn{5}{|c|}{ Período de 1 a 40 dias } \\
\hline Sem aditivo & 2419 & 2382 & 3734 & 1,57 \\
\hline Antibiótico & 2458 & 2420 & 3728 & 1,54 \\
\hline Prebiótico & 2473 & 2435 & 3713 & 1,55 \\
\hline Jejum & 2411 & 2373 & 3701 & 1,56 \\
\hline SEM & 180 & 180 & 156 & 0,09 \\
\hline \multicolumn{5}{|l|}{$\mathrm{P}-$ valor } \\
\hline Tratamento $(\mathrm{T})$ & 0,849 & 0,848 & 0,235 & 0,889 \\
\hline Bloco (B) ${ }^{1}$ & 0,394 & 0,394 & 0,067 & 0,708 \\
\hline Interação $T^{*} B$ & 0,850 & 0,848 & 0,216 & 0,935 \\
\hline
\end{tabular}

${ }^{1}$ Blocos: peso médio dos pintinhos no incubatório de 39,77g ou de 40,66g. Tratamentos: Sem aditivo Ração sem aditivo nas fases pré e pós-alojamento; Antibiótico - Ração com antibiótico nas fases pré e pós-alojamento; Prebiótico - Ração com prebiótico nas fases pré e pós-alojamento; Jejum - Jejum na fase pré-alojamento e ração sem aditivo na fase pós-alojamento. 
Em relação aos aditivos utilizados na ração, Flemming et al. (2005) e Dalólio et al. (2015), também não encontraram diferença significativa para desempenho entre frangos que receberam antibiótico, prebiótico, probiótico, simbiótico e $\mathrm{o}$ controle. Entretanto, Nunes et al. (2009) observaram melhores valores para ganho de peso e conversão alimentar de frangos que receberam antibiótico em comparação com os que receberam prebiótico, probiótico e o controle (sem aditivo). A microbiota intestinal é extremamente sensível e dinâmica, portanto as condições do ambiente, status nutricional e desafios sanitários exercem forte influencia sobre a composição e relação dos microorganismo presentes (SAVAGE, 1977). Além disso, o advento da utilização de criações intensivas e a ausência de contato prévio dos pintinhos com a microbiota natural, no momento da eclosão, tornam as aves susceptíveis a adquirirem enfermidades (DALÓLIO et al., 2015). Por estes e outros fatores, os resultados de experimentos com aditivos equilibradores da flora podem ser conflitantes, em virtude de que as condições experimentais nem sempre representam de maneira fiel, o que ocorre no campo. Em um galpão experimental as condições ambientais e estruturais geralmente são melhores, ocorre maior higiene de pessoal e equipamentos, menor desafio sanitário, melhor manejo das aves (gerando menor estresse) e maior tempo devazio sanitário das instalações (FLEMMING, 2005).

O fornecimento de ração pré-alojamento, assim como a utilização de aditivos antibiótico ou prebiótico, não influenciou $(\mathrm{P}<0,05)$ o fator de produção $\mathrm{e} a$ viabilidade percentual de frangos de corte de 1 a 40 dias (Tabela 4). Esses resultados corroboram os achados por Agostinho et al. (2012) e Almeida et al. (2006). Silva et al. (2009) verificou maior viabilidade em aves que consumiram prebiótico em comparação com aves que não receberam nenhum aditivo, fato este não observado neste experimento e também por outros autores (FLEMMING et al., 2005; ALBINO et al., 2006; DALÓLIO et al., 2015).

Tabela 4. Efeito do uso de aditivos antibiótico ou prebiótico na ração pré- alojamento (trajeto incubatório-granja) e pós-alojamento (de 1 a 40 dias) sobre a viabilidade $(\%)$ e o fator de produção $(\mathrm{FP})$ de frangos de corte

\begin{tabular}{|c|c|c|}
\hline Tratamentos & Viabilidade $\%$ & FP \\
\hline Sem aditivo & 92,26 & 350 \\
\hline Antibiótico & 96,43 & 380 \\
\hline Prebiótico & 97,86 & 370 \\
\hline Jejum & 95,24 & 363 \\
\hline SEM & 1,86 & 12,13 \\
\hline \multicolumn{3}{|l|}{$\mathrm{P}$ - valor } \\
\hline Tratamento $(\mathrm{T})$ & 0,468 & 0,397 \\
\hline Bloco $(B)^{1}$ & 0,999 & 0,055 \\
\hline Interação $T^{*} B$ & 0,073 & $0,028^{*}$ \\
\hline
\end{tabular}

${ }^{\mathrm{I}}$ Blocos: peso médio dos pintinhos no incubatório de $39,77 \mathrm{~g}$ ou de $40,66 \mathrm{~g} .{ }^{2} \mathrm{~A}$ interação do tratamento pelo bloco foi dada porque para o tratamento 1 teve diferenças entre os blocos 1 e 2, mas para os outros tratamentos não houve diferenças entre os blocos.

Tratamentos: Sem aditivo - Ração sem aditivo nas fases pré e pós-alojamento; Antibiótico - Ração com antibiótico nas fases pré e pós-alojamento; Prebiótico - Ração com prebiótico nas fases pré e pósalojamento; Jejum - Jejum na fase pré-alojamento e ração sem aditivo na fase pós-alojamento. 
Rev. Bras. Saúde Prod. Anim., Salvador, v.17, n.4, p.719-728 out./dez., 2016 http://www.rbspa.ufba.br ISSN 15199940

O uso de rações contendo prebióticos e antibióticos nas fases pré e pós alojamento não promove melhora no desempenho de frangos de corte, que foram alimentados com essas rações em comparação com frangos que sofreram jejum durante 24 horas após a eclosão.

\section{AGRADECIMENTOS}

Agradecemos aos professores Normand R. StPierre e Dr. Amélia Almeida pela sua assistência na análise estatística e também a CAPES pela concessão da bolsa de estudos.

\section{REFERÊNCIAS}

AGOSTINHO, T.S.P.; CALIXTO, L.F.L.; GOMES, A. V. D. C.; TOGASHI, C.K.; CURVELLO, F.A.; LIMA, M.F.de. Desenvolvimento de órgãos do trato gastrintestinal e desempenho de frangos de corte arraçoados na fase préalojamento. Revista Brasileira de Saúde e Produção Animal [online], v.13, n.4, p.1143-1155, 2012.

ALBINO, L.F.T.; FERES, F.A.; DIONIZIO, M.A.; ROSTAGNO, H.S.; VARGAS JR. J.G.; CARVALHO D.C.O.; GOMES, P.C.; COSTA, C.H.R. Uso de prebióticos à base de mananoligossacarídeo em rações para frangos de corte. Revista Brasileira de Zootecnia, v.35, n.3, p.742-749, 2006.

ALMEIDA, J.G.; DAHLKE, F.; MAIORKA, A.; MACARI, M.; FURLAN, R. L. Efeito do jejum no intervalo entre o nascimento e o alojamento sobre o desempenho de frangos de corte provenientes de matrizes de diferentes idades. Archives of Veterinary Science, v.11, n.2, p.50-54, 2006.
CANALLI, L.S.; FLEMMING, J.S.; MIRA, R.T.; BASILE, L.F. Alteração da microbiota intestinal de frangos de corte pela utilização de um probiótico na alimentação. Revista do Setor de Ciências Agrárias, v.15, n.1, p.125-133, 1996.

CORLESS, A.B.; SELL, J. L.The effects of delayed access to feed and water on the physical and functional development of the digestive system of young turkeys.

Poultry Science, v.78, n.8, p.1158-1169, 1999.

DALMAGRO, M. Influência da nutrição neonatal no desempenho produtivo e sanitário de frangos de corte. Vetanco, 2012. Disponivel em:

$<$ http://www.vetanco.com.br/wpcontent/uploads/2012/11/Influencia-danutricao-neonatal-no-desempenhoprodutivo-e-sanitario-de-frangos-decorte-DVM-MSc-MarceloDalmagro.pdf $>$. Acesso em: 5 jan. 2012.

DALÓLIO, F.S.; MOREIRA, J.; VALADARES, L.R.; NUNES, P.B.; VAZ, D.P.; PEREIRA, H.J.; PIRES, A.V.; DA CRUZ, P.J. Aditivos alternativos ao uso de antimicrobianos na alimentação de frangos de corte. Revista Brasileira de Agropecuária Sustentável, v.5, n.1, 2015.

FLEMMING, J.S. Utilização de leveduras, probióticos e mananoligossacarídeos na alimentação de frangos de corte. 2005. 111f. Tese (Doutorado em Tecnologia de Alimentos) - Universidade Federal do Paraná, Curitiba.

GEYRA, A.; UNI, Z.; SKLAN, D. The effect of fasting at different ages on growth and tissue dynamics in the small intestine of the young chick. British Poultry Science, v.86, p.53-61, 2001. 
Rev. Bras. Saúde Prod. Anim., Salvador, v.17, n.4, p.719-728 out./dez., 2016 http://www.rbspa.ufba.br ISSN 15199940

IJI, P.A.; SAKI, A.A.; TIVEY, D.R. Intestinal structure and function of broiler chickens on diets supplemented with a mannan oligosaccharide.

Journal of the Science of Food and Agriculture, v.81, n.12, p.1186-1192, 2001.

MAZZUCO, H.; GUIDONI, A.L.; JAENISCH, F.R. Efeito da restrição alimentar qualitative sobre o ganho compensatório em frangos de corte. Pesquisa Agropecuária Brasileira, v.35, n.3, p.543-549, 2000.

NOY, Y.; SKLAN, D. Metabolic responses to early nutrition. Journal Applied Poultry Research, v.7, n.4, p.437-451, 1998.

NOY, Y.; SKLAN, D. Hydrolysis and Absorption in the Small Intestines of Post hatch Chicks. Poultry Science, v.79, n.9, p.1306-1310, 2000.

NUNES, A.D.; VAZ, A.C.N.; RASPANTINI, L.E.; DA SILVA, E.M.; DE ALBUQUERQUE, R. Desempenho e morfologia intestinal de frangos de corte alimentados com rações contendo aditivos alternativos a antimicrobianos.

Brazilian Journal of Veterinary Research and Animal Science, v.46, n.6, p.500-506, 2009.

PEDROSO A.A; BARBOSA C.E; STRINGHINIJ. H; BARCELLOS, C.M; MOGYCA L.N.S; TEIXEIRA, B.V Intervalo Entre a retirada do nascedouro e o Alojamento de pintos de diferentes pesos oriundos de matrizes jovens. Ciência Animal Brasileira, v.7, n.3, p.249-256, 2006.

ROSTAGNO, H.S.; ALBINO, L.F.T.; DONZELE, J.L.; GOMES, P.C.; OLIVEIRA, R.F.; LOPES, D.C.; FERREIRA, A.S.; BARRETO, S.L.T.; EUCLIDES, R.F. Tabelas brasileiras para aves e suínos: composição de alimentos e exigências nutricionais. Viçosa, MG: UFV, 2011. 252p.

SAKI, A.A. Effect of post-hatch feeding on broiler performance. International Journal of Poultry Science, v.4, n.1, p.4-6, 2005.

SAVAGE, D.C. Microbial ecology of the gastrointestinal tract. Annual Veterinary Microbiology, v.31, n.1, p.107-133, 1977.

SILVA, K.S.; SILVA, J.D.T.; GRAVENA, R.A.; MARQUES, R.H.; HADA, F.H.; MORAES, V.M.B. Desempenho de frangos de corte de 1 a 21 dias de idade alimentados com rações contendo extrato de leveduras e prebiótico e criados em diferentes temperaturas. Revista Brasileira de Zootecnia, v.38, n.4, p.690-696, 2009.

UNI, Z.; NOY, Y.; SKLAN, D. Posthatch development of muscosal function in the broiler small intestine. Poultry Science, v.77, p.75-82, 1998.

Data de recebimento: 23/02/2016 Data de aprovação: 15/09/2016 